\title{
Recent Progress in Cardiovascular Research Involving Single-Cell Omics Approaches
}

\author{
Zhehao Dai and Seitaro Nomura* \\ Department of Cardiovascular Medicine, Graduate School of Medicine, The University of Tokyo, Tokyo, Japan
}

Cardiovascular diseases are among the leading causes of morbidity and mortality worldwide. Although the spectrum of the heart from development to disease has long been studied, it remains largely enigmatic. The emergence of single-cell omics technologies has provided a powerful toolbox for defining cell heterogeneity, unraveling previously unknown pathways, and revealing intercellular communications, thereby boosting biomedical research and obtaining numerous novel findings over the last 7 years. Not only cell atlases of normal and developing hearts that provided substantial research resources, but also some important findings regarding cell-type-specific disease

OPEN ACCESS

Edited by:

Christoph Dieterich,

Heidelberg University, Germany

Reviewed by:

Robert Kelly,

UMR7288 Institut de Biologie du Développement de Marseille (IBDM), France

Monika Gladka,

Academic Medical

Center, Netherlands

*Correspondence:

Seitaro Nomura

senomura-cib@umin.ac.jp

Specialty section:

This article was submitted to Cardiovascular Genetics and Systems Medicine,

a section of the journal

Frontiers in Cardiovascular Medicine

Received: 26 September 2021

Accepted: 22 November 2021

Published: 16 December 2021

Citation:

Dai $Z$ and Nomura S (2021) Recent

Progress in Cardiovascular Research Involving Single-Cell Omics Approaches.

Front. Cardiovasc. Med. 8:783398.

doi: 10.3389/fcvm.2021.783398 gene program, could never have been established without single-cell omics technologies. Herein, we briefly describe the latest technological advances in single-cell omics and summarize the major findings achieved by such approaches, with a focus on development and homeostasis of the heart, myocardial infarction, and heart failure.

Keywords: single-cell omics, cardiovascular research, heart development, cardiac homeostasis, myocardial infarction, heart failure

\section{INTRODUCTION}

Cardiovascular diseases are among the major causes of morbidity and mortality worldwide. Yet, despite relentless research efforts in recent decades, the complex structure of the heart, its incessantly beating nature, and its wide range of abnormalities and disorders made us still struggle to understand the molecular mechanisms underlying the normal development, homeostasis, and diseases of this organ.

Recent technological advances have enabled researchers to understand biology at the single-cell resolution. Single-cell RNA sequencing (scRNA-seq) and single-cell assay for transposase-accessible chromatin sequencing (scATAC-seq) allow an unbiased assessment of transcriptomics and epigenomics in heterogeneous tissues and have identified not only previously unknown cell populations, but also dynamic cellular transitions and intercellular interactions in various tissues $(1,2)$. These cutting-edge technologies have been applied not only to healthy humans and mice to create reference maps, namely, the Human Cell Atlas and the Tabula Muris $(3,4)$, but also to normal development and various diseases. Recent advances in spatial transcriptomics, the molecular profiling method that compensates for the lack of spatial information in scRNA-seq, have furthered our understanding (5). The use of singlecell omics technologies in cardiovascular research has been increasing exponentially since 2015 (Figure 1) and, as expected, is providing more insight into the workings of both healthy and pathological hearts.

In this review, we briefly introduce the latest technological advances in single-cell omics and summarize recent progress in cardiovascular research that has applied these technologies, with 


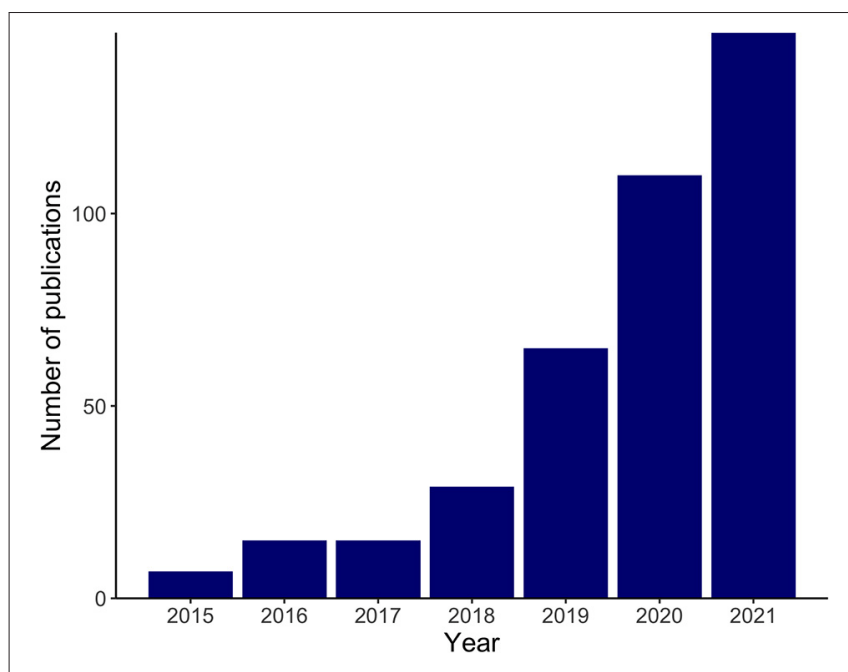

FIGURE 1 | Exponential increase in cardiovascular research implementing single-cell omics. The bar plot shows the numbers of search results in PubMed in recent years with the following search term and the search conducted on November 2, 2021: ("RNA-Seq"[Mesh] OR "Transcriptome"[Mesh] OR "Chromatin Immunoprecipitation Sequencing"[Mesh] OR multi-omics[Title/Abstract] OR multiomics[Title/Abstract] OR omics[Title/Abstract] OR sequencing[Title/Abstract] OR seq[Title/Abstract]) AND ("Single-Cell Analysis"[Mesh] OR "single cell"[Title/Abstract] OR "single nucleus"[Title/Abstract] OR "single nuclei"[Title/Abstract]) AND ("heart"[Mesh] OR heart[Title/Abstract] OR cardiac[Title/Abstract] OR cardiomyocyte[Title/Abstract] OR myocardial[Title/Abstract]).

special focus on development and homeostasis of the heart, myocardial infarction (MI) and ischemia, and heart failure (HF). We also discuss how single-cell omics can, and should support future cardiovascular research and contribute to precision cardiovascular medicine.

\section{TECHNOLOGICAL ADVANCES}

The experimental pipelines of single-cell omics, represented by scRNA-seq, typically begin with single-cell isolation and capture, followed by sequencing and downstream analyses (6). In the early days, integrated fluidic circuit (IFC) systems, such as Fluidigm C1, were used to isolate cells into individual chambers, where they were then lysed and reverse-transcribed (platebased method). The IFC system has been largely replaced by fluorescence-activated cell sorting (FACS), which can not only isolate cells, but also distinguish live cells through viability stains. A major drawback of plate-based systems, however, is the limited number of cells that can be analyzed. To overcome this, droplet-based methods were developed, in which single cells are encapsulated in droplets and then undergo barcoding and reverse transcription. This technology has greatly improved throughput, increasing the number of cells analyzed to up to 10,000 cells, albeit with a sacrifice in read depth.

Both IFC systems used in plate-based methods and microfluidic devices used in droplet-based methods limit the size of the cells that can be processed to $<\sim 40 \mu \mathrm{m}$, which are applicable to non-cardiomyocytes, neonate cardiomyocytes
(CMs), and pluripotent stem cell-derived CMs. However, adult CMs ( $>100 \mu \mathrm{m}$ in length) cannot be processed by these methods. Moreover, commercially available FACS nozzles $(70-130 \mu \mathrm{m}$ in diameter) might induce terminal damage to live CMs and so are not suitable either $(6,7)$. Although successful isolation of viable single CMs using large-particle FACS with a nozzle of $500 \mu \mathrm{m}$ in diameter has recently been reported (8), most published studies applying scRNA-seq in CMs have relied on either manual pick-up of CMs combined with plate-based methods (9) or the iCELL8 system, a large nozzle dispenser with a 5,184-nanowell plate and an imaging system to differentiate live cells from dead ones (10). An alternative solution is to isolate and sequence the single nuclei of CMs (11), which are smaller and can pass through FACS and droplet-based systems. Single-nucleus RNA sequencing (snRNA-seq), although is applicable in archived frozen specimens and can minimize the alteration of gene expression that may be caused by dissociation (12), should be used and its results interpreted with awareness of how it differs from scRNA-seq. A comparison of snRNA-seq and scRNA-seq showed that they both demonstrated similar cell clusters in the process of induced pluripotent stem cell (iPSC) differentiation to CMs. However, scRNA-seq captures more genes than snRNA-seq, represented by mitochondrial and ribosomal genes, while snRNA-seq detects more non-coding RNA and more reads that are mapped to intronic regions $(11,13)$. Importantly, the multinucleation and polyploidy of CMs also contribute to the divergence of snRNA-seq from scRNA-seq when applied to CMs, thus should be taken into consideration (14).

Besides the advances made in single-cell transcriptomics, its integration with single-cell epigenomics, namely, scATACseq, provides more information on both cell clustering and interactions between gene expression and open chromatin states $(15,16)$. Furthermore, spatial transcriptomics (i.e., technologies that recover transcriptomic information from tissue while preserving its spatial localization) is undergoing exponential development. Spatial transcriptomics uses either multiplexed RNA imaging [e.g., sequential fluorescence in situ hybridization (seqFISH)] or spatial barcoding (e.g., Visium, slide-seq) (5). Because the structure of the heart is complex and its tissues are highly heterogeneous, the addition of spatial information substantially improves our understanding of tissue architectures. It is also better able to uncover intercellular communications, thereby boosting the exploration of the underlying molecular pathways in the developing, normal, and diseased heart $(5,17)$.

In the following sections of this review, we focus on recent cardiovascular research that has applied single-cell omics technologies.

\section{DEVELOPMENT OF THE HEART}

Early scRNA-seq studies of the heart mainly focused on its development because fetal and neonatal cardiac tissues are easier to digest and their cells, including CMs, are smaller and so can pass through various single-cell platforms. Several such studies are highlighted in Table $\mathbf{1}$. 
TABLE 1 | Summary of studies of heart development.

\begin{tabular}{|c|c|c|c|c|c|}
\hline References & Species & Developmental stage & Target tissues/cells & Modalities & Major findings \\
\hline Chan et al. (18) & Mouse & $\begin{array}{l}\text { Mouse ESC-derived embryoid } \\
\text { bodies day } 4\end{array}$ & Dissociated cells from embryoid bodies & scRNA-seq & Mesp $1^{+}$mesoderm cells are highly heterogeneous \\
\hline Lescroart et al. (19) & Mouse & Embryonic day 6.25 and 7.5 & Mesp1+ or Mesp1 KO CPCs & scRNA-seq & $\begin{array}{l}\text { Mesp1 was essential for cell exit from the pluripotent state and the } \\
\text { induction of the cardiac gene expression program }\end{array}$ \\
\hline DeLaughter et al. (20) & Mouse & $\begin{array}{l}\text { Embryonic day } 9.5,11.5,14.5 \text {, } \\
\text { and } 18.5 ; \text { postnatal day } 0,3 \text {, } \\
\text { and } 21\end{array}$ & $\begin{array}{l}\text { Microdissected embryonic heart tissues of } \\
\text { each chamber }\end{array}$ & scRNA-seq & $\begin{array}{l}\text { Single cells were classified into CMs, ECs, and fibroblast-enriched } \\
\text { cells. Markers of temporal- and chamber-specific developmental } \\
\text { programs were identified. Nkx2-5 haploinsufficiency delayed } \\
\text { developmental programs in both CMs and ECs }\end{array}$ \\
\hline Li et al. (21) & Mouse & $\begin{array}{l}\text { Embryonic day } 8.5,9.5 \text {, and } \\
10.5\end{array}$ & $\begin{array}{l}\text { Microdissected embryonic heart tissues of } \\
\text { each chamber }\end{array}$ & scRNA-seq & $\begin{array}{l}\text { Using a random forest algorithm, the origins of single CMs were } \\
\text { successfully reconstructed. Loss of Nks2-5 led to failed differentiation } \\
\text { into ventricular CMs }\end{array}$ \\
\hline Jia et al. (15) & Mouse & Embryonic day $7.5,8.5$, and 9.5 & $1 s / 1^{+}$or $N k \times 2-5^{+}$CPCs & $\begin{array}{l}\text { scRNA-seq and } \\
\text { scATAC-seq }\end{array}$ & $\begin{array}{l}\text { Is/1+ CPCs passed through an attractor state before segregating into } \\
\text { different developmental branches. Continued expression of } N k \times 2-5 \\
\text { established a unidirectional cardiomyocyte fate for CPCs }\end{array}$ \\
\hline Xiong et al. (22) & Mouse & $\begin{array}{l}\text { Embryonic day } 7.75,8.25 \text {, and } \\
9.75\end{array}$ & $1 s / 1^{+}$or $N k \times 2-5^{+}$CPCs & $\begin{array}{l}\text { scRNA-seq, } \\
\text { CHIP-seq }\end{array}$ & $\begin{array}{l}\text { CPCs in first and second heart fields exhibited different differentiation } \\
\text { kinetics toward CMs. FHF cardiomyocytes guided the migration of SHF } \\
\text { cells through the MIF-CXCR2/CXCR4 chemotaxis }\end{array}$ \\
\hline Ivanovitch et al. (23) & Mouse & $\begin{array}{l}\text { Embryonic day } 6.9 \text { (mid to late } \\
\text { streak), day } 7.1 \text { (no-bud to } \\
\text { early-bud), and day } 7.3 \text { (early } \\
\text { headfold), }\end{array}$ & $\begin{array}{l}\text { Tamoxifen treated } \\
T^{T E G F P-C r e E R T 2 /+} ; R 26 R^{\text {tdTomato/tdTomato embryos }}\end{array}$ & scRNA-seq & $\begin{array}{l}\text { scRNA-seq demonstrated that the primitive streak cells contributing to } \\
\text { the ventricles had a distinct molecular signature from those forming the } \\
\text { outflow tract and atria, suggesting that cardiac progenitors were } \\
\text { prepatterned in the primitive streak before migration. }\end{array}$ \\
\hline de Soysa et al. (24) & Mouse & $\begin{array}{l}\text { Embryonic day } 7.75,8.25 \text {, and } \\
9.25\end{array}$ & CPCs from control and Hand2-null embryos & scRNA-seq & $\begin{array}{l}\text { Hand2 was a specifier of outflow tract cells. Hand2-null mouse } \\
\text { embryos failed to develop the right ventricle, which was due to failure of } \\
\text { outflow tract myocardium specification }\end{array}$ \\
\hline Xiao et al. (25) & Mouse & Embryonic day 13.5 and 14.5 & $\begin{array}{l}\text { Cardiac tissue from control or Lats } 1 / 2 \\
\text { conditional (epicardium) KO mice }\end{array}$ & scRNA-seq & $\begin{array}{l}\text { Lats } 1 / 2 \text { in EPDCs were essential for their differentiation into cardiac } \\
\text { fibroblasts and for coronary vessel remodeling }\end{array}$ \\
\hline Quijada et al. (26) & Mouse & $\begin{array}{l}\text { Embryonic day } 12.5 \text { and } 16.5 ; \\
\text { embryonic day } 14.5\end{array}$ & $\begin{array}{l}\text { EPDCs from control at embryonic day } 12.5 \text { and } \\
\text { 16.5; from conditional KO of myocardin-related } \\
\text { transcription factors in the epicardium, } \\
\text { embryonic day } 14.5\end{array}$ & scRNA-seq & $\begin{array}{l}\text { Slit2 }{ }^{+} \text {EPDCs emerged following EMT. Genetic disruption of EMT } \\
\text { altered the expression of vascular guidance cues such as Slit2 and } \\
\text { disturbed EC maturation and localization in the coronary vasculature }\end{array}$ \\
\hline Sereti et al. (27) & Mouse & $\begin{array}{l}\text { Embryonic day } 9.5 \text { and } 12.5 \text { and } \\
\text { postnatal day } 1\end{array}$ & $\alpha \mathrm{MHC}^{+}$cardiomyocytes & scRNA-seq & $\begin{array}{l}\text { Expression of cell cycle genes decreased to a minimal level postnatally, } \\
\text { along with CM maturation }\end{array}$ \\
\hline Su et al. (28) & Mouse & Embryonic day 12.5 and 14.5 & $\begin{array}{l}\text { Sinus venosus-derived ECs from control at } \\
\text { embryonic day } 12.5 \text {; from control and } \mathrm{Nr} 2 \mathrm{f2} \\
\text { overexpression hearts at embryonic day } 14.5\end{array}$ & scRNA-seq & $\begin{array}{l}\text { Vein cells underwent an early cell fate switch to pre-artery ECs. NR2F2 } \\
\text { inhibited the pre-artery population via the induction of cell cycle genes }\end{array}$ \\
\hline Li et al. (29) & Mouse & Embryonic day 10.5 & $\begin{array}{l}\text { Cardiac cells from dissected heart chambers } \\
\text { and } / s / 1^{+} \text {cardiac cells }\end{array}$ & scRNA-seq & $\begin{array}{l}\text { CMs in G2/M phase downregulated sarcomeric and cytoskeletal } \\
\text { markers }\end{array}$ \\
\hline $\begin{array}{l}\text { Wunnemann et al. } \\
\text { (30) }\end{array}$ & Mouse & Embryonic day 14.5 & Wild-type and Adamts 19-null heart cells & scRNA-seq & $\begin{array}{l}\text { Adamts } 19 \text { was a marker gene of valvular interstitial cells. Gene } \\
\text { regulatory network analysis positioned Adamts } 19 \text { in a network } \\
\text { downstream of the WNT signaling pathway }\end{array}$ \\
\hline
\end{tabular}


TABLE 1 | Continued

\begin{tabular}{|c|c|c|c|c|c|}
\hline References & Species & Developmental stage & Target tissues/cells & Modalities & Major findings \\
\hline Hulin et al. (31) & Mouse & Postnatal day 7 and 30 & Cells from aortic and mitral valve leaflets & scRNA-seq & $\begin{array}{l}\text { Subpopulations of endothelial and immune cells were comparable } \\
\text { between the two time points, whereas interstitial cells were more } \\
\text { diverse at postnatal day } 30 \text {, expressing complement factors, ECM } \\
\text { proteins, and osteogenic genes }\end{array}$ \\
\hline Wang et al. (32) & Mouse & Postnatal day 1, 4, 7, 14 and 56 & $\mathrm{CMs}$ and non-CMs from left ventricles & scRNA-seq & $\begin{array}{l}\text { Genes involved in ECM organization, BMP signaling pathway and CM } \\
\text { differentiation were enriched in mature fibroblasts when compared with } \\
\text { immature ones. Maturation of CMs were promoted when co-cultured } \\
\text { with adult fibroblasts, but not with neonatal fibroblast. }\end{array}$ \\
\hline Goodyer et al. (33) & Mouse & Embryonic day 16.5 & $\begin{array}{l}\text { Cells from three zones of microdissected } \\
\text { hearts: sinoatrial node region, atrioventricular } \\
\text { node/His region, and bundle branch/Purkinje } \\
\text { fiber region }\end{array}$ & scRNA-seq & $\begin{array}{l}\text { The study revealed clusters of sinoatrial node cells, atrioventricular } \\
\text { node/His cells, and Purkinje fiber and transitional Purkinje fiber cells, as } \\
\text { well as their cell subtypes, and thus delineated the first transcriptional } \\
\text { landscape of the developing cardiac conduction system }\end{array}$ \\
\hline $\begin{array}{l}\text { Suryawanshi et al. } \\
\text { (34) }\end{array}$ & Human & 19-22 weeks gestation & $\begin{array}{l}\text { Cells from healthy or autoimmune-associated } \\
\text { CHB fetal hearts }\end{array}$ & scRNA-seq & $\begin{array}{l}\text { Fetal heart with autoimmune-associated CHB exhibited varying } \\
\text { degrees of increased interferon responses in all cell types. Matrisome } \\
\text { transcripts were highly enriched in the fibroblasts and smooth muscle } \\
\text { cells in the CHB sample }\end{array}$ \\
\hline Sahara et al. (35) & Human & $\begin{array}{l}\text { Human ESC-derived cardiac } \\
\text { lineages day } 3,6 \text {, and } 15 \text {; } \\
\text { human embryonic/fetal hearts } \\
4.5-10 \text { weeks gestation }\end{array}$ & $\begin{array}{l}\text { Human ESC-derived cardiac lineages; human } \\
\text { embryonic/fetal cardiac cells }\end{array}$ & scRNA-seq & $\begin{array}{l}\text { Cono-ventricular progenitors were marked by } L G R 5 \text {, which is } \\
\text { human-specific. } L G R 5^{+} \text {progenitors promoted cardiogenesis via } \\
\text { expansion of committed cardiac intermediates }\end{array}$ \\
\hline Cui et al. (36) & Human & 5-25 weeks gestation & $\begin{array}{l}\text { Anatomically informed cardiac cells from } \\
\text { human embryos }\end{array}$ & scRNA-seq & $\begin{array}{l}\text { The study identified major cell types and demonstrated the similarities } \\
\text { in and differences between humans and mice }\end{array}$ \\
\hline Lahm et al. (37) & Human/mouse & $\begin{array}{l}4.5-10 \text { weeks gestation and } \\
\text { adults }\end{array}$ & $\begin{array}{l}\text { Human embryonic/fetal cardiac cells; adult } \\
\text { human atrial and ventricular cells }\end{array}$ & scRNA-seq & $\begin{array}{l}\text { The four detected genes-MACROD2, GOSR2, WNT3, and } \\
\text { MSX1-were highly expressed throughout development, and } \\
\text { MACROD2 remained expressed in adult heart }\end{array}$ \\
\hline Asp et al. (38) & Human & $\begin{array}{l}4.5-5,6.5 \text {, and } 9 \text { weeks } \\
\text { post-conception }\end{array}$ & Human embryonic/fetal cardiac cells & $\begin{array}{l}\text { scRNA-seq, } \\
\text { spatial } \\
\text { barcoding, and } \\
\text { in situ } \\
\text { sequencing }\end{array}$ & $\begin{array}{l}\text { The study generated the first spatiotemporal cell atlas for the } \\
\text { developing human heart }\end{array}$ \\
\hline Tyser et al. (39) & Mouse & $\begin{array}{l}\text { Embryonic day } 7.75-8.25 \\
\text { (divided into six stages) }\end{array}$ & Microdissected anterior cardiac region & $\begin{array}{l}\text { scRNA-seq, } \\
\text { multiplexed RNA } \\
\text { imaging }\end{array}$ & $\begin{array}{l}\text { A previously unknown CPC pool marked by Mab2112 was identified, } \\
\text { which contributed to not only CMs, but also the epicardium }\end{array}$ \\
\hline Mantri et al. (40) & Chicken & $\begin{array}{l}\text { Embryonic day } 4,7,10 \text {, and } 14 \\
\text { (corresponding to } \mathrm{HH} 21-24 \text {, } \\
\mathrm{HH} 30-31, \mathrm{HH} 35-36 \text {, and } \\
\sim \mathrm{HH} 40 \text { ) }\end{array}$ & $\begin{array}{l}\text { Enzymatically digested cardiac ventricular } \\
\text { tissues }\end{array}$ & $\begin{array}{l}\text { scRNA-seq, } \\
\text { spatial } \\
\text { barcoding, and } \\
\text { multiplexed RNA } \\
\text { imaging }\end{array}$ & $\begin{array}{l}\text { Spatially restricted genes during development were identified. The } \\
\text { study also discovered a TMSB } 4 \text {-expressing subpopulation that } \\
\text { overlapped coronary vascular cells throughout coronary development }\end{array}$ \\
\hline
\end{tabular}

CHB, congenital heart block; ChIP-seq, chromatin immunoprecipitation with parallel sequencing; CM, cardiomyocyte; CPC, cardiac progenitor cell; EC, endothelial cell; EMT, epithelial-to-mesenchymal transition; ESC, embryonic stem cell; FHF, first heart field; HH, Hamburger-Hamilton; KO, knockout; SCATAC-seq, single-cell assay for transposase-accessible chromatin sequencing; sCRNA-seq, single-cell RNA sequencing; SHF, second heart field. 
It had been unclear whether $M e s p 1^{+}$mesoderm cells were intrinsically heterogeneous or were homogeneous but capable of multiple lineage decisions. Taking advantage of scRNA-seq, Chan et al. unraveled the heterogeneity of $\mathrm{Mesp}^{+}$mesoderm cells from mouse embryonic stem cell (ESC)-derived embryoid bodies (18). Lescroart et al., by examining $M e s p 1^{+}$cardiac progenitor cells (CPCs) as well as Mesp1-expressing cells in the Mesp1 knockout context, found that Mesp1 was essential for exit from the pluripotent state and for induction of the cardiac gene expression program (19).

Efforts to establish a transcriptomic atlas of the developing heart have been undertaken by multiple teams. By investigating $>1,200$ cells from murine heart chambers of different developmental stages, DeLaughter et al. not only successfully clustered CMs, endothelial cells (ECs), and fibroblast-enriched cells, but also identified markers of temporal- and chamberspecific developmental programs (e.g., genes involved in cell cycle at embryonic day 9.5-11.5 and genes involved in cellular growth and CM differentiation between embryonic day 14.5 and postnatal day 3) (20). Li et al. used a similar approach together with a random forest algorithm to reconstruct the spatial origins of single CMs (21). Both studies demonstrated that Nkx2-5 deficiency led to failure of CM maturation $(20,21)$. Jia et al. integrated scRNA-seq and scATAC-seq in $N k \times 2-5^{+}$ and $I s l 1^{+} \mathrm{CPCs}$, enabling developmental trajectories to be reconstructed and revealing that $I s l 1^{+} \mathrm{CPCs}$ passed through an attractor state before segregating into different developmental branches, whereas continued expression of $N k \times 2-5$ established a unidirectional CM fate for CPCs (15). A similar analysis of $N k \times 2-5^{+}$and $I s l 1^{+}$CPCs found interactions between first and second heart field CPCs, with second heart field CPCs attracted to the first heart field-populated heart tube region through MIF (macrophage migration inhibitory factor)-CXCR2/CXCR4 chemotaxis, contributing to the growth of the outflow tract and right ventricle (22). Furthermore, using genetic lineage tracing and live imaging, Ivanovitch et al. discovered the temporal order in which different cardiac lineages arose within the primitive streak: the progenitors of the left ventricle at the mid-streak stage, those of the right ventricle at the late-streak stage, and those of the outflow tract and atria at the no-bud to early-bud stage. More importantly, scRNA-seq demonstrated distinct molecular signatures of these subpopulations of primitive streak cells, indicating their prepatterned fate in the primitive streak before migration (23). Using a Boolean network-based lineage-specifier prediction method in the downstream analysis of scRNA-seq of mouse embryos as an alternative approach, de Soysa et al. identified Hand2 as a specifier of outflow tract cells. Hand2-null mouse embryos failed to specify outflow tract myocardium, whereas the right ventricle myocardium was specified but not properly differentiated and migrated, which was associated with disrupted anterior-posterior patterning of CPCs (24).

With a focus on epicardium-derived cells (EPDCs), Xiao et al. demonstrated that epicardium conditional knockout of Lats1/2, encoding LATS1 and LATS2 that are negative regulators in the Hippo signaling pathway, caused arrested differentiation into fibroblasts and defective coronary vasculature remodeling (25). Quijada et al. also investigated epicardial contributions to the growing coronary plexus by applying scRNA-seq to EPDCs and uncovered a Slit2 ${ }^{+}$subpopulation that emerged following epithelial-to-mesenchymal transition (EMT). Genetic disruption of EMT altered the expression of vascular guidance cues such as Slit2 and disturbed EC maturation and localization in the coronary vasculature (26). Su et al. analyzed sinus venosusderived ECs, discovered that the vein cells underwent an early cell fate switch to pre-artery ECs, and identified the transcription factor NR2F2 as a vein specifier, whose overexpression prevented differentiation to the pre-artery population via the induction of cell cycle genes (28). By performing a genome-wide association study (GWAS) in humans, Wunnemann et al. detected mutations in ADAMTS19 that are responsible for valvular diseases. They then applied scRNA-seq to wild-type and Adamts19-null murine heart at embryonic day 14.5 and identified Admats19 as a marker of valve interstitial cells. Gene regulatory network analysis helped to identify the WntAdamts19-Klf2 axis as being essential for valve development (30). Another study of murine postnatal valve leaflets demonstrated that, whereas subpopulations of ECs and immune cells were comparable between day 7 and 30, interstitial cells were more diverse at postnatal day 30, expressing complement factors, extracellular matrix proteins, and osteogenic genes (31). Wang et al. analyzed the dynamic change of subtypes of non-CMs along with postnatal CM maturation in murine hearts. scRNAseq of CMs and non-CMs of murine hearts at postnatal day $1,4,7,14$, and 56 showed that fibroblasts increasingly expressed maturation promoting genes such as Dcn. Coculture experiments demonstrated that maturation of CMs was promoted when co-cultured with adult fibroblasts, but not with neonatal fibroblasts. Their results indicated fibroblasts subtype switching as a crucial microenvironmental event regulating postnatal CM maturation (32).

Development of the conduction system has also attracted researchers' interest. Goodyer et al. performed scRNA-seq on cells from murine embryonic heart regions including the conduction system. The study revealed clusters of sinoatrial node cells, atrioventricular node/His cells, and Purkinje fiber and transitional Purkinje fiber cells, thus delineated the first transcriptional landscape of the developing cardiac conduction system (33). Suryawanshi et al. investigated singlecell transcriptomes from healthy human fetal hearts and a fetal heart with autoimmune-associated congenital heart block and showed, through a comparison with normal fetal hearts, that the fetal heart with autoimmune-associated congenital heart block exhibited increased interferon responses of varying degrees in all cell types. Additionally, matrisome transcripts were highly enriched in the fibroblasts and smooth muscle cells in the congenital heart block sample compared with healthy hearts, indicating their contribution to fibrosis (34).

Other studies of human heart development, although rare, have also been conducted to unravel the human-specific features. Cui et al. identified cell types from human fetal hearts and compared their gene expression profiles with those of mice (36). A study of human ESC-derived cardiac derivates and human embryonic/fetal hearts revealed a human-specific conoventricular progenitor population marked by LGR5. LGR5 
(leucine rich repeat containing G protein-coupled receptor 5) is a receptor for R-spondins, which is involved in the WNT signaling pathway. $L G R 5^{+}$progenitors were shown to promote cardiogenesis via expansion of committed cardiac intermediates (35). Lahm et al. identified four congenital heart diseaseassociated genes-MACROD2, GOSR2, WNT3, and MSX1by GWAS and explored their expression in embryonic and adult human heart by scRNA-seq. They found that MACROD2, GOSR2, WNT3, and MSX1 were highly expressed throughout development and that MACROD2 expression persisted in adult heart (37).

More recent research implemented multiple advanced technologies along with scRNA-seq. Asp et al. generated the first spatiotemporal cell atlas for human developing heart by integrating scRNA-seq, spatial barcoding, and multiplexed RNA imaging (38). Tyser et al., by combining scRNA-seq with genetic lineage labeling and abundant imaging modalities including multiplexed RNA in situ hybridization in murine embryonic hearts, identified and located the CPC subpopulations. Via this spatial transcriptomic approach, they unraveled a previously unknown progenitor subpopulation marked by Mab21l2 that located at the rostral border of the cardiac crescent and contributed to both CMs and epicardium. Mab2112 (Mab21 like 2) was previously known to be required for neural and eye development, was here implied to represent the earliest progenitors of the epicardium (39). By integrating scRNA-seq and spatial transcriptomics in developing chicken hearts, Mantri et al. identified spatially restricted genes in cardiac tissue during development. They found that TBX5 was enriched in the left ventricle compared with the right but decreased from embryonic day 7 to 14 and that $C H G B$ expression was restricted to the right ventricle from day 7 onward. In addition, they discovered a TMSB4X-expressing subpopulation that overlapped with coronary vascular cells throughout coronary development. TMSB4 (thymosin $\beta 4$ ) participates in regulating actin polymerization, thus is involved in cell proliferation, migration, and differentiation. Its role in heart development had long been under significant debate, given the paradoxical results of several previous Tmsbx knockout and knockdown experiments in mouse models, and was provided deeper insights into by this study (40). Undoubtedly, the latest technological advances, represented by spatial transcriptomics, are furthering our understanding of the molecular mechanisms of cardiac development.

\section{HOMEOSTASIS OF THE ADULT HEART}

Single-cell omics approaches have also been implemented in studies of adult mice and humans in homeostasis (Table 2), with more studies focusing on non-CMs than on CMs. Yekelchyk et al. performed scRNA-seq on murine CMs using the iCELL8 platform, finding that gene expression was homogeneous between mono- and multi-nucleated CMs in heathy ventricles (41). By performing scRNA-seq on non-CMs of murine heart, Skelly et al. detected major cell types and transcriptional heterogeneity, revealed communications between cell types, and showed cell type-specific sexual dimorphism of cardiac gene expression, such as male upregulation of Irf8 (interferon regulatory factor 8) and female upregulation of $T s c 22 d 3$ (TSC22 domain family member 3 , a transcription factor implicated in anti-inflammatory functions) in macrophages. Their results provided molecular cues for the sexual difference of cardiac responses to the environmental insults (42). Chakarov et al. identified two distinct interstitial macrophage populations occupying different niches, which were conserved across lung, heart, fat, and dermis tissues: Lyve $1^{\text {low }} \mathrm{MHCII}{ }^{\text {high }} \mathrm{CX} 3 \mathrm{CR} 1^{\text {high }}$ and Lyve $1^{\text {high }} \mathrm{MHCII}{ }^{\text {low }} \mathrm{CX} 3 \mathrm{CR} 1^{\text {low }}$ monocyte-derived interstitial macrophages. They also demonstrated that depletion of Lyve ${ }^{\text {high }} \mathrm{MHCII}^{\text {low }} \mathrm{CX} 3 \mathrm{CR} 1^{\text {low }}$ interstitial macrophages exacerbated lung and heart fibrosis (43), which was highly consistent with the results obtained using a mouse MI model (55). Macrophages also facilitate conduction in the atrioventricular node. Genes involved in cardiac conduction are enriched in macrophages from the atrioventricular node when compared with those from other tissues. Atrioventricular node macrophages highly express $C \times 43$, contributing to the gap junctions that link them to neighboring CMs (44). In regard to the conduction system, quantitative proteomics of the murine sinus node demonstrated a remarkable abundance of ion channels responsible for the pacemaking process (e.g., HCN4), which were indicated by snRNA-seq to be predominantly expressed by sinus node myocytes (45). Liang et al. then verified the existence of a cell cluster in the sinus node marked by $H c n 1$ and Hcn4, where Vsnl1 was also highly expressed. VSNL1 (visinin-like 1) is a member of visinin/recoverin subfamily of neuronal calcium sensor proteins, and is involved in calcium signaling pathways. Adeno-associated virus-mediated knockdown of Vsnl1 in mice resulted in a reduced heart rate and decreased expression of Hcn4, Cacnald, Cacnali, and Serca2a, but not that of Ryr2 or of the genes involved in potassium channels (46).

Cardiac ECs are another research interest. Paik et al. reexplored the scRNA-seq data from tissue-specific ECs in the Tabula Muris (4) and demonstrated that cardiac ECs could be classified as a separate cluster, even though they had considerable transcriptomic overlap with ECs from other tissues (47). Yucel et al. unexpectedly observed that adult murine cardiac ECs actively expressed cardiac myofibril genes such as Tnnt2 and Myh6, which was consistent with the analytical results of multiple datasets; this result was validated by RNA in situ hybridization. They also showed that cardiac ECs had open chromatins at cardiac myofibril gene promoters, suggesting that the results were not due to technical contamination or paracrine transfer of mRNA. Interestingly, the accessibility of cardiac myofibril genes was no longer maintained in cardiac ECs upon culture. Although the significance of the expression of cardiac myofibril genes in cardiac ECs is still unclear, the authors hypothesized that those genes played a role in maintaining cardiac EC maturity and specificity, which needs further investigation (48). Hu et al. used scRNA-seq to analyze cells from human aorta, pulmonary artery, and coronary arteries collected from patients who underwent heart transplantation. Artery-specific cell subpopulations with distinct transcriptional profiles were 
TABLE 2 | Summary of studies of homeostasis of the adult heart.

\begin{tabular}{|c|c|c|c|c|}
\hline References & Species & Target tissues/cells & Modalities & Major findings \\
\hline Yekelchyk et al. (41) & Mouse & $\begin{array}{l}\text { CMs from both healthy and hypertrophic } \\
\text { ventricles }\end{array}$ & scRNA-seq & $\begin{array}{l}\text { Gene expression was homogeneous between mono- and multi-nucleated CMs in } \\
\text { homeostasis. Heterogeneity was introduced by TAC }\end{array}$ \\
\hline Skelly et al. (42) & Mouse & Non-CMs from the heart & scRNA-seq & $\begin{array}{l}\text { Major cell types and transcriptional heterogeneity were detected, as well as communications } \\
\text { among cell types. The study also showed cell type-specific sexual dimorphism of cardiac gene } \\
\text { expression }\end{array}$ \\
\hline Chakarov et al. (43) & Mouse & $\begin{array}{l}\text { Lung interstitial macrophages (validated in the } \\
\text { heart, fat, and skin by flow cytometry) }\end{array}$ & scRNA-seq & $\begin{array}{l}\text { Two distinct IM populations conserved across the lung, heart, fat, and dermis tissues were } \\
\text { identified. Depletion of Lyve } 1^{\text {high }} \mathrm{MHC} \|^{\text {low }} \mathrm{CX} 3 \mathrm{CR} 1^{\text {low }} \mid \mathrm{Ms} \text { exacerbated lung and heart fibrosis }\end{array}$ \\
\hline Hulsmans et al. (44) & Mouse & Macrophages in the AV nodes & scRNA-seq & $\begin{array}{l}\text { Genes involved in cardiac conduction were enriched in macrophages from the AV node } \\
\text { compared with those from other tissues. AV node macrophages highly expressed Cx43, } \\
\text { forming the gap junctions linking them to neighboring CMs }\end{array}$ \\
\hline Linscheid et al. (45) & Mouse & $\begin{array}{l}\text { Cells from sinus node tissue and the adjacent } \\
\text { atrium }\end{array}$ & $\begin{array}{l}\text { snRNA-seq, bulk } \\
\text { proteomics }\end{array}$ & $\begin{array}{l}\text { Quantitative proteomics of murine sinus node demonstrated significant abundancy of ion } \\
\text { channels responsible for the pacemaking process (e.g., HCN4), which were predominantly } \\
\text { expressed by sinus node myocytes, as revealed by snRNA-seq }\end{array}$ \\
\hline Liang et al. (46) & $\begin{array}{l}\text { Mouse, rabbit, } \\
\text { monkey }\end{array}$ & $\begin{array}{l}\text { Cells from microdissected sinus node tissues } \\
\text { and those from atrial and ventricular CMs }\end{array}$ & scRNA-seq & $\begin{array}{l}\text { A cell cluster expressing } H c n 1, H c n 4 \text {, and } V s n / 1 \text { was found. Knockdown of Vsn/1 in mice } \\
\text { resulted in reduced heart rate and decreased Hcn4, Cacna1d, Cacna1i, and Serca2a } \\
\text { expression, but not that of Ryr2 or those involved in potassium channels }\end{array}$ \\
\hline Paik et al. (47) & Mouse & $\begin{array}{l}\text { scRNA-seq data from tissue-specific ECs from } \\
\text { the Tabula Muris }\end{array}$ & scRNA-seq & $\begin{array}{l}\text { Cardiac ECs could be classified as a separate cluster but had considerable transcriptomic } \\
\text { overlap with ECs from other tissues. Markers of tissue-specific ECs identified in mice were also } \\
\text { enriched in their corresponding human tissue-specific ECs }\end{array}$ \\
\hline Yucel et al. (48) & Mouse & ECs and non-ECs from murine heart & $\begin{array}{l}\text { Bulk RNA-seq, } \\
\text { snRNA-seq, bulk } \\
\text { ATAC-seq, multiplexed } \\
\text { RNA imaging }\end{array}$ & $\begin{array}{l}\text { Cardiac ECs actively expressed cardiac myofibril genes such as Tnnt2 and Myh6 and had } \\
\text { open chromatin at cardiac myofibril gene promoters }\end{array}$ \\
\hline Hu et al. (49) & Human & $\begin{array}{l}\text { Cells from human aorta, pulmonary artery, and } \\
\text { coronary arteries collected from patients } \\
\text { undergoing heart transplantation }\end{array}$ & scRNA-seq & $\begin{array}{l}\text { Artery-specific cell subpopulations with distinct transcriptional profiles were identified in VSMCs } \\
\text { and fibroblasts, but not in ECs. Intercellular communication between macrophages and ECs } \\
\text { was predicted to increase in atherosclerosis }\end{array}$ \\
\hline Wolfien et al. (50) & Mouse & Nuclei isolated from entire murine hearts & snRNA-seq & $\begin{array}{l}\text { Distinct cell clusters were identified, including immune cells and cells of neuronal origin. RNA } \\
\text { velocity enabled interrogation of transcriptional kinetics }\end{array}$ \\
\hline Vidal et al. (51) & Mouse & $\begin{array}{l}\text { Nuclei isolated from entire hearts of } \\
\text { 12-week-old and 18-month-old mice }\end{array}$ & snRNA-seq & $\begin{array}{l}\text { Angiogenesis-related extracellular protein-encoding genes including Serpine1 and Serpine2 } \\
\text { were enriched in fibroblasts derived from aged hearts, indicating an affected paracrine } \\
\text { crosstalk between fibroblasts and ECs during aging. Conditioned medium derived from aged } \\
\text { fibroblasts had higher levels of serpins and showed a reduced angiogenic property, which was } \\
\text { mediated by an impairment of EC function }\end{array}$ \\
\hline Tucker et al. (52) & Human & $\begin{array}{l}\text { Tissue samples taken from the lateral aspect of } \\
\text { the four cardiac chambers from potential } \\
\text { transplant donors }\end{array}$ & snRNA-seq & $\begin{array}{l}\text { CMs were the most heterogeneous of various cell types. When combined with GWAS data, } \\
\text { genes at the loci associated with heart rhythm were enriched in CMs, whereas those } \\
\text { associated with CAD were enriched in pericytes }\end{array}$ \\
\hline Litvinukova et al. (53) & Human & $\begin{array}{l}\text { Full-thickness myocardial biopsies from the left } \\
\text { and right atria, left and right ventricles, and } \\
\text { interventricular septum and apex from } \\
\text { deceased transplant organ donors }\end{array}$ & $\begin{array}{l}\text { scRNA-seq, snRNA-seq, } \\
\text { and multiplexed RNA } \\
\text { imaging }\end{array}$ & $\begin{array}{l}\text { CMs, pericytes, and fibroblasts were the most heterogeneous. Predicted intercellular } \\
\text { communications among CMs, fibroblasts, and immune cells differed between atria and } \\
\text { ventricles }\end{array}$ \\
\hline Wang et al. (54) & Mouse & Murine heart non-myocytes & scRNA-seq, scATAC-seq & $\begin{array}{l}\text { Differential accessibilities of the cis-regulatory elements among different subpopulations in each } \\
\text { cell type that potentially regulate the expression of marker genes }\end{array}$ \\
\hline
\end{tabular}


identified in vascular smooth muscle cells and fibroblasts, but not in ECs (49).

Recently, efforts have focused on depicting the full picture of the cell atlas of the whole heart. snRNA-seq of murine hearts successfully clustered distinct cell subpopulations, including immune cells, cells of neuronal origin, and cardiac glial cells (50). With snRNA-seq, Vidal et al. investigated the transcriptomes of murine hearts of 12-week-old and 18-month-old, and found upregulated angiogenesis-related extracellular proteinencoding genes in aged hearts, indicating an affected paracrine crosstalk between fibroblasts and ECs during aging. In vitro experiments confirmed that conditioned medium derived from aged fibroblasts showed a reduced angiogenic property, which was mediated by an impairment of EC function (51). In humans, samples of myocardium from cardiac chambers, rather than of the whole heart, have been studied. By applying snRNA-seq to biopsied human cardiac chambers, Tucker et al. showed that CMs were the most spatially heterogeneous of the distinct cell types. Furthermore, by combining the snRNAseq results with GWAS data for cardiometabolic traits, they revealed that genes at the loci associated with heart rhythm were enriched in CMs, whereas those at the loci associated with coronary artery disease were enriched in pericytes (52). Litvinukova et al. investigated full-thickness biopsy samples from deceased transplant donors and were able to provide more in-depth information, predicting different intercellular communications among immune cells, CMs, and fibroblasts between ventricles and atria (53). Wang et al. integrated scRNA-seq and scATAC-seq for non-CMs in murine hearts and revealed the heterogeneity of non-CM populations and their subpopulations at transcriptomic and epigenomic levels. Cardiac fibroblasts were classified into three distinct functional states related to response to stimuli (marked by Hsd11b1; $11 \beta$-hydroxysteroid dehydrogenase type 1 ), the cytoskeleton (marked by Gfpt2; glutaminefructose-6-phosphate transaminase 2 , involved in the hexosamine biosynthesis pathway), and immune regulation (marked by C1qa), respectively. Importantly, they also identified differential accessibilities of the cis-regulatory elements among different subpopulations of each cell type that potentially regulate the expression of marker genes (54). The success of these studies indicates that single-cell omics represents an indispensable toolbox for broadening our insights into the homeostasis of the adult heart, particularly the heterogeneity of cells and their functions, as well as intercellular communications.

\section{MYOCARDIAL INFARCTION/ISCHEMIA-REPERFUSION INJURY}

In addition to development and adult homeostasis, single-cell omics approaches have played a crucial role in research into diseased hearts (Table 3). MI, as a consequence of atherosclerotic disease, may have a marked effect on cardiac function and quality of life. The toolbox from single-cell omics technologies has enabled detailed investigation of not only the cells involved in the process of plaque formation and rupture, but also the ischemic myocardium that is susceptible to remodeling (71).

MI has long been known to involve both pro- and antiinflammatory cascades. King et al. were the first to apply scRNA-seq to leukocytes isolated from infarcted and noninfarcted murine hearts, finding that MI induced an IRF3dependent type I interferon response in a distinct subpopulation of cardiac macrophages and that interruption of IRF3-dependent signaling decreased the cardiac expression of inflammatory cytokines and chemokines and improved cardiac function (56). Cardiac-infiltrating neutrophils were demonstrated to locally acquire a SiglecF ${ }^{\text {high }}$ ICAM $^{\text {high }}$ CXCR $4^{\text {high }}$ state from day 3 after MI, indicating local neutrophil activation and aging. Similar neutrophil subpopulation was also found in atherosclerotic aortas, suggesting their roles both in acute and chronic cardiovascular inflammation (57). Regulatory $\mathrm{T}$ cells (Tregs) accumulated in the injured myocardium after MI or ischemiareperfusion injury. The majority of these heart Tregs were derived from the circulating Treg pool; a considerable fraction of them experienced clonal expansion and displayed a unique T-cell receptor repertoire. Importantly, extracellular matrix-associated genes, including Sparc, were enriched in heart Tregs compared with other Tregs. Further experiments revealed that heart Tregs contributed to increased collagen content and prevented rupture and that Sparc was critical in this process (58). After MI, cardiac B cells also accumulated rapidly via the CXCL13CXCR5 axis but were largely polyclonal and contributed to local TGF $\beta$ production, indicating their involvement in fibroblast activation (59).

Fibroblasts are directly involved in post-infarct scar formation. Gladka et al. performed scRNA-seq on cells sorted by FACS with a $130-\mu \mathrm{m}$ nozzle from infarcted and control murine hearts and were able to identify distinct clusters of CMs, fibroblasts, ECs, and macrophages. A subset of activated fibroblasts was revealed to be specific to injured hearts and to strongly express Ckap4. CKAP4 (cytoskeleton associated protein 4) is a transmembrane receptor whose function in cardiac fibroblasts had remained unknown. In vitro inhibition of Ckap4 resulted in increased expression of genes related to activated fibroblasts after TGF $\beta$ induction, suggesting a modulating function for CKAP4 in fibroblast activation (60). Molenaar et al. focused on the ligands upregulated in CMs 1 day after ischemia, whose cognate receptors were expressed by another cell type, and detected $B 2 m$ ( $\beta 2$ microglobulin) in CMs and its receptors in fibroblasts. In vitro experiments demonstrated that fibroblasts expressed myofibroblast markers when cultured with B2M (61). Farbehi et al. discovered a novel fibroblast subpopulation with upregulated Wif1 expression, in sham hearts, which persisted after MI, had an anti-WNT/CTGF/TGF $\beta$ signature, and interacted with ECs. Immunofluorescence revealed WIF1 ${ }^{+}$ fibroblasts in close proximity with ECs in the border zone at post-MI day 3, but not in sham or post-MI day 1 or 7 hearts, indicating the injury-dependent and post-transcriptional regulation of WIF expression, and its function of inhibiting fibrosis and angiogenesis in post-MI repair (62). By investigating the murine heart 14 days after MI, Kretzschmar et al. identified a subpopulation of proliferative fibroblasts resembling neonatal 
TABLE 3 | Summary of studies of myocardial infarction or ischemia-reperfusion injury.

\begin{tabular}{|c|c|c|c|c|c|}
\hline References & Species & Ischemia model & Target tissues/cells & Modalities & Major findings \\
\hline King et al. (56) & Mouse & $\begin{array}{l}\text { Permanent ligation } \\
\text { of left coronary } \\
\text { artery }\end{array}$ & $\begin{array}{l}\text { Leukocytes isolated from wild-type and } \\
\text { IIf3-null heart at day } 4 \text { post-Ml or sham }\end{array}$ & scRNA-seq & $\begin{array}{l}\text { MI induced an IRF3-dependent type I interferon response in a distinct subpopulation } \\
\text { of cardiac macrophages. Interruption of IRF3-dependent signaling decreased the } \\
\text { cardiac expression of inflammatory cytokines and chemokines and improved cardiac } \\
\text { function and survival }\end{array}$ \\
\hline Vafadarnejad et al. (57) & Mouse & $\begin{array}{l}\text { Permanent ligation } \\
\text { of } L A D\end{array}$ & $\begin{array}{l}\text { Neutrophils isolated from infarcted hearts } \\
\text { and blood at day } 1,3 \text {, and } 5 \text { post-Ml or } \\
\text { sham }\end{array}$ & $\begin{array}{l}\text { scRNA-seq, } \\
\text { CITE-seq }\end{array}$ & $\begin{array}{l}\text { Post-Ml cardiac neutrophils were temporally heterogeneous. Infiltrating neutrophils } \\
\text { were demonstrated to locally acquire a SiglecFigh state at day } 3 \text { onward after Ml, in } \\
\text { which transcripts associated with neutrophil aging and activation were also enriched }\end{array}$ \\
\hline Xia et al. (58) & Mouse & $\begin{array}{l}\text { Permanent ligation } \\
\text { of } L A D ; 60 \text {-min } \\
\text { ligation of } L A D\end{array}$ & $\begin{array}{l}\text { Regulatory and conventional T cells from } \\
\text { heart, spleen, non-draining LNs, and } \\
\text { mediastinal LNs at day } 7 \text { post-Ml or sham }\end{array}$ & $\begin{array}{l}\text { Bulk RNA-seq, } \\
\text { scRNA-seq, } \\
\text { scTCR-seq }\end{array}$ & $\begin{array}{l}\text { Tregs were recruited to the injured myocardium after Ml or I/R injury from the } \\
\text { circulating Treg pool. A considerable fraction of heart Tregs was clonally expanded. } \\
\text { ECM-associated genes, including Sparc, were enriched in heart Tregs. Heart Tregs } \\
\text { led to increased collagen content and prevented rupture, with Sparc playing a critical } \\
\text { role in this process }\end{array}$ \\
\hline Heinrichs et al. (59) & Mouse & $\begin{array}{l}\text { Permanent ligation } \\
\text { of } L A D\end{array}$ & $\begin{array}{l}\text { B cells from heart and mediastinal LNs at } \\
\text { day } 5 \text { post-Ml or sham }\end{array}$ & $\begin{array}{l}\text { scRNA-seq, } \\
\text { scBCR-seq }\end{array}$ & $\begin{array}{l}\text { Cardiac B cells accumulated rapidly after MI via the CXCL13-CXCR5 axis. These cells } \\
\text { were largely polyclonal and contributed to local TGF } \beta \text { production. CXCR5-deficiency } \\
\text { reduced B cell infiltration and local Tgfb1 expression but did not change post-Ml } \\
\text { contractile function or myocardial morphology }\end{array}$ \\
\hline Gladka et al. (60) & Mouse & $\begin{array}{l}\text { 75-min ligation of } \\
\text { left coronary artery }\end{array}$ & $\begin{array}{l}\text { Cells from the infarct and border zone } \\
\text { region from infarcted heart at day } 3 \\
\text { post-Ml or sham }\end{array}$ & scRNA-seq & $\begin{array}{l}\text { A subcluster of fibroblasts was revealed to be specific to injured hearts, highly } \\
\text { expressing Ckap4, along with well-known myofibroblast markers such as Postn and } \\
\text { Cthrc1. In vitro inhibition of Ckap4 resulted in increased expression of myofibroblasts } \\
\text { after TGF } \beta \text { induction }\end{array}$ \\
\hline Molenaar et al. (61) & Mouse & $\begin{array}{l}\text { 60-min ligation of } \\
\text { LAD }\end{array}$ & $\begin{array}{l}\text { Cells from non-infarct regions from the } \\
\text { heart at day } 1,3 \text {, and } 14 \text { post-injury or } \\
\text { sham }\end{array}$ & scRNA-seq & $\begin{array}{l}\text { Mfge8, Calr and B2m were upregulated in CMs at day } 1 \text { post-injury, with their } \\
\text { cognate receptors expressed in other cell types (dominantly in fibroblasts). B2M } \\
\text { induced the expression of myofibroblast markers in fibroblasts in vitro }\end{array}$ \\
\hline Farbehi et al. (62) & Mouse & $\begin{array}{l}\text { Permanent ligation } \\
\text { of } L A D\end{array}$ & $\begin{array}{l}\text { All non-CMs and enriched (Pdgfra-GFP }{ }^{+} \text {) } \\
\text { fibroblast lineage cells from ventricles at } \\
\text { day } 3 \text { and } 7 \text { post-Ml or sham }\end{array}$ & scRNA-seq & $\begin{array}{l}\text { A novel fibroblast subpopulation expressing Wif1 was discovered in both sham and } \\
\text { post-MI hearts, which presented an anti-WNT/CTGF/TGF } \beta \text { signature, and interacted } \\
\text { with ECs. IF revealed WIF1+ fibroblasts in the border zone at post-MI day 3, but not } \\
\text { in sham or post-MI day } 1 \text { or } 7 \text { hearts, indicating the post-transcription and } \\
\text { injury-dependent regulation of WIF expression, and its function of inhibiting fibrosis } \\
\text { and angiogenesis }\end{array}$ \\
\hline Kretzschmar et al. (63) & Mouse & $\begin{array}{l}\text { Permanent ligation } \\
\text { of } L A D ; 60 \text {-min } \\
\text { ligation of } L A D\end{array}$ & $\begin{array}{l}\text { Cells from neonatal heart or adult heart } 14 \\
\text { days after } \mathrm{Ml}, \mathrm{I} / \mathrm{R} \text {, or sham }\end{array}$ & scRNA-seq & $\begin{array}{l}\text { By investigating murine heart } 14 \text { days after MI with genetic lineage tracing using Ki67 } \\
\text { knockin models, no cycling CMs were found in infarcted hearts. A subpopulation of } \\
\text { proliferative fibroblasts expressing Fst/1 was identified, which resembled neonatal } \\
\text { cardiac fibroblasts. Conditional KO of Fst/1 in fibroblasts resulted in more rupture }\end{array}$ \\
\hline Forte et al. (64) & Mouse & $\begin{array}{l}\text { Permanent ligation } \\
\text { of } L A D\end{array}$ & $\begin{array}{l}\text { Cardiac interstitial cells at post-Ml day } 1 \text {, } \\
3,5,7,14 \text {, and } 28 \text { or sham }\end{array}$ & scRNA-seq & $\begin{array}{l}\text { Epicardial-derived injury-response fibroblasts arose immediately after Ml and were } \\
\text { replaced by myofibroblasts, followed by matrifibrocytes and late-response fibroblasts. } \\
\text { Different strains of mice exhibited different post-Ml dynamics of fibroblasts, which } \\
\text { was related to cardiac rupture }\end{array}$ \\
\hline Yokota et al. (65) & Mouse & $\begin{array}{l}\text { Permanent ligation } \\
\text { of } L A D\end{array}$ & $\begin{array}{l}\text { Non-CMs from heart at post-Ml day } 7 \text { in } \\
\text { wild-type and Col5a conditional } \mathrm{KO} \text { (in } \\
\text { fibroblasts) mice }\end{array}$ & scRNA-seq & $\begin{array}{l}\text { Deficiency in type } \mathrm{V} \text { collagen resulted in a paradoxical increase in post-Ml scar tissue } \\
\text { with altered mechanical properties of scars and myofibroblast induction }\end{array}$ \\
\hline Li et al. (66) & Mouse & $\begin{array}{l}\text { Permanent ligation } \\
\text { of } L A D\end{array}$ & $\begin{array}{l}\text { Cardiac ECs from post-MI day } 7 \text { or sham } \\
\text { heart in EC-specific multispectral lineage } \\
\text { tracing mice }\end{array}$ & scRNA-seq & $\begin{array}{l}\text { Clonal proliferation of resident ECs occurred in the infarct border zone. } \\
\text { Subpopulations of ECs expressing P/vap increased after MI. In vitro inhibition of Plvap } \\
\text { reduced EC proliferation }\end{array}$ \\
\hline Tombor et al. (67) & Mouse & $\begin{array}{l}\text { Permanent ligation } \\
\text { of } L A D\end{array}$ & $\begin{array}{l}\text { Cardiac non-CMs from post-Ml day } 1,3 \text {, } \\
5,7,14 \text {, and } 28 \text { or sham }\end{array}$ & scRNA-seq & ECs underwent transient mesenchymal transition on days 3-7 after MI \\
\hline
\end{tabular}




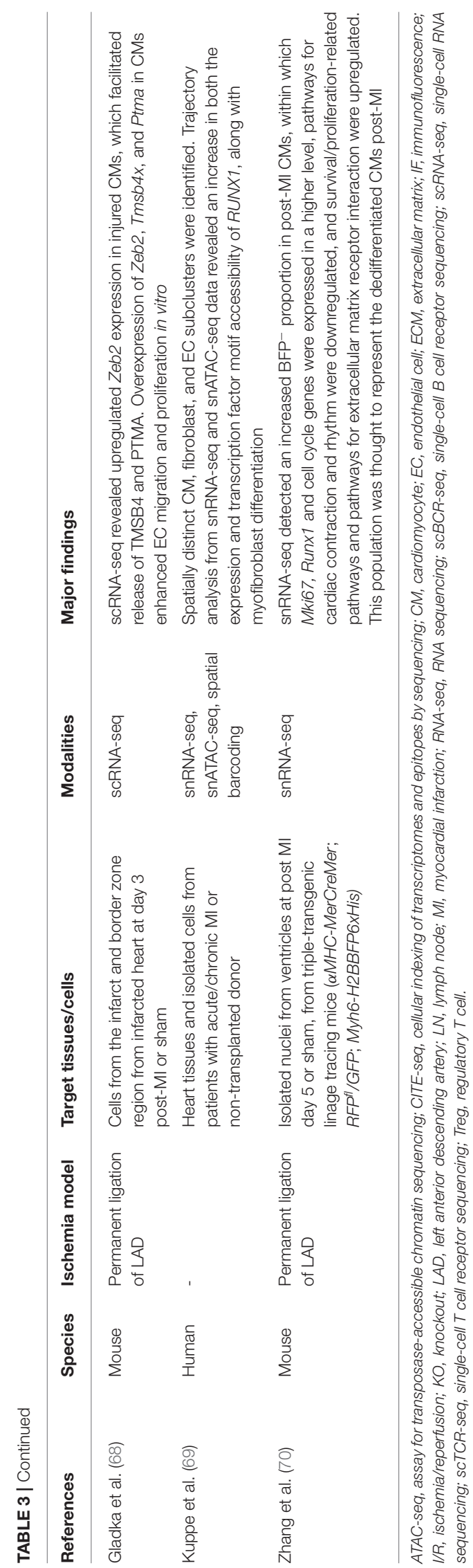

cardiac fibroblasts, which presented with upregulated Fstl1 (follistatin-like 1, which had been known to be expressed in adult cardiac fibroblasts). Conditional knockout of Fstl1 in fibroblasts induced less proliferative cells at the infarct and border zones and lead to more cardiac ruptures, indicating the importance of autocrine FSTL1 signaling in preventing rupture (63). Longitudinal scRNA-seq analysis of murine heart interstitial cells from post-MI day 1 to 28 uncovered a dynamic shift in the subpopulations. In particular, epicardial-derived injury-response fibroblasts arose immediately after MI and were replaced by myofibroblasts, followed by matrifibrocytes and late-response fibroblasts. Different strains of mice exhibited different post-MI dynamics of fibroblasts, which was related to the risk of cardiac rupture (64). Yokota et al. demonstrated that a deficiency in type $\mathrm{V}$ collagen resulted in a paradoxical increase of scar tissue, where mechanical properties of scars were altered, and myofibroblasts were induced (65).

ECs are involved in angiogenesis after MI and have thus been another target of single-cell studies. Li et al. discovered that clonal proliferation of resident ECs occurred in the infarct border zone, in which Plvap was enriched. PLVAP (plasmalemma vesicle associated protein) had been known as an EC-specific membrane protein involved in the formation of transendothelial channels and microvascular permeability. In vitro inhibition of Plvap reduced EC proliferation, indicating its involvement in neoangiogenesis (66). Li et al. also observed transient endothelial mesenchymal activation, but the extent to which was comparable between post-MI day 7 and sham. By contrast, Tombor et al. demonstrated that ECs underwent transient mesenchymal activation on days 1 to 7 after MI, which returned to homeostasis afterwards, indicating its involvement in facilitating regeneration of the vascular network via EC migration and clonal expansion (67). A crosstalk between injured CMs and ECs has also been identified: transcription factor Zeb2 expression was upregulated in injured $\mathrm{CMs}$, which facilitated the release of TMSB4 and PTMA (prothymosin $\alpha$ ). Overexpression and knockdown experiments of Zeb2, Tmsb4x, and Ptma in iPSC-derived CMs clearly demonstrated their involvement in enhancing EC proliferation and migration (68).

Kuppe et al. integrated snRNA-seq, single-nucleus assay for transposase-accessible chromatin sequencing (snATACseq), and spatial transcriptomics in human heart tissues from patients with and without a history of MI. Trajectory analysis from snRNA-seq and snATAC-seq data revealed an increase in both the expression and the transcription factor motif accessibility of RUNX1 in fibroblasts, as well as in their differentiation to myofibroblasts. In vitro experiments then validated that RUNX1 amplified TGF $\beta$ signaling and thus mediated myofibroblast differentiation (69). Zhang et al. developed a triple-transgenic mouse model $(\alpha M H C-M e r C r e M e r$; $R F P^{f l} / G F P$; Myh6-H2BBFP6xHis, tamoxifen treated) for fate mapping of CMs after MI. They discovered an increase in the rare $\mathrm{GFP}^{+} \mathrm{BFP}^{\text {low }} \mathrm{CMs}$ in post-MI hearts compared to sham hearts that presented with a high $\mathrm{BrdU}^{+}$incorporation rate, which were thought to represent dedifferentiated CMs. snRNAseq also detected an increased $\mathrm{BFP}^{-}$proportion in post-MI CMs, within which Mki67, Runx1, and cell cycle genes were 
expressed in a higher level. They further showed that pathways for cardiac contraction and rhythm were downregulated, and pathways for survival/proliferation and extracellular matrix receptor interaction were upregulated (70).

MI is not a local event but rather a spatiotemporally heterogeneous state of disease involving the entire heart. The conventional approach for increasing the spatial resolution in earlier studies was dissecting infarct hearts into ischemic zone, border zone, and remote zone. To this end, spatial transcriptomics adds a continuous spatial resolution to the transcriptomic information, which is being used in ongoing research into MI.

\section{HEART FAILURE AND MISCELLANEOUS}

HF presents with various underlying causes and culminates in cardiac dysfunction and pump insufficiency, with the most often used experimental animal model of HF being transverse aorta constriction (TAC)-induced pressure overload in mice (Table 4). See et al. investigated single nuclei from CMs in the mouse pressure overload model, in which CMs accurately segregated into clusters specific to sham or TAC groups. Weighted gene co-expression network analysis (WGCNA) revealed a disease module in which the long non-coding RNAs (lncRNAs) Gas5 and Sghrt were identified as key nodal regulators and were correlated with cell cycle genes and the fetal reprogramming marker $N p p a$, providing early evidence for IncRNA-regulated state alteration in stress-response CMs (72). Nomura et al. investigated CMs at various time points after TAC and revealed that activated p53 signaling in the late stage of hypertrophy facilitated the HF gene program (73). They also analyzed single-cardiomyocyte transcriptomes from patients with HF and confirmed the conservation of pathological gene programs. Ren et al. used the iCELL8 platform for scRNA-seq of both CMs and non-CMs in murine hearts after TAC and revealed that fibroblasts underwent a subtype switching away from protective features at the initial stage of hypertrophy. The study also showed that the macrophages switched toward a pro-inflammatory state and that their considerable interaction with $\mathrm{CMs}$ was associated with deterioration of cardiac function (74). With the iCELL8 platform, Wang et al. constructed a comprehensive resource of single-cell transcriptomes of both CMs and non-CMs from normal, failed, and recovered human heart biopsy samples. In addition to revealing the inter- and intra-compartmental CM heterogeneity, a major finding of this study was that ACKR $1^{+}$ECs, which had a protective function and possessed the highest counts of interactions with other cell types, decreased in failed hearts. This observation was validated by in vivo experiments where injection of ACKR $1^{+}$ECs rescued cardiac function after MI by increasing vessel density in both infarct and border regions in mice (10). Zaman et al. demonstrated that cardiac macrophages in the acute and chronic phase after angiotensin II-induced hypertensive stress were enriched in IgfIcontaining reparative pathways related to wound healing and angiogenesis and that conditional knockout of Igfl in tissueresident macrophages inhibited adaptive CM hypertrophy and led to cardiac dysfunction after long-term hypertensive stress
(75). Besides the interaction with CMs, cardiac macrophages have also been reported to activate fibroblasts through paracrine signaling in HF. Ramanujam et al. applied ligand-receptor pair analysis to scRNA-seq data from non-CMs in pressureoverloaded murine hearts by analyzing the transcripts of secreted protein ligands in one cell type and their receptors in another cell type, and predicted that M1 like macrophages interacted with activated fibroblasts via secreted proteins such as TGF $\beta$ and fibronectin. These interactions were demonstrated to be mediated by macrophage miR-21, depletion of which rescued hypertrophic phenotype after TAC (76). Martini et al., by sequencing cardiac $\mathrm{CD}_{4} 5^{+}$cells, showed increases in $\mathrm{Osm}^{+}$ pro-inflammatory macrophages, as well as $P d c d 1^{+}$Tregs, in pressure-overloaded murine hearts when compared with healthy hearts (77).

Single-cell omics approaches have also played important roles in recent studies investigating SARS-CoV-2-associated cardiac injury. ACE2 (the cellular receptor for virus spike protein) is expressed in CMs and pericytes and is upregulated at both mRNA and protein levels in failing hearts, indicating a vulnerability of these cell states to infection $(78,79)$. By combining phosphoproteomics and snRNA-seq, Mills et al. reported that the inflammatory response in human cardiac organoids was mediated by STAT1 and epigenetic activation, including BRD4 (bromodomain containing 4, a member of bromodomain and extraterminal protein family). They then validated the results in the hearts of SARS-CoV-2-infected K18-hACE2 mice. Bromodomain and extraterminal family inhibitors were identified as drug candidates that could prevent COVID-19-mediated cardiac damage (80).

\section{FUTURE PERSPECTIVES}

Single-cell omics technologies are advancing rapidly and are being applied to a wide range of research subjects. Meanwhile, enabled by progress in bioinformatic analysis, the integration of multi-omics data, as well as spatial transcriptomics, is becoming more common and is providing us with more comprehensive information. These technologies offer deeper insights into the molecular pathways involved in heart development, homeostasis, and specifically in cardiovascular diseases and are thus helping to identify therapeutic candidates.

Besides elucidating pathophysiology, single-cell omics can also contribute to precision medicine. The response to treatment in cardiovascular diseases is non-uniform, as in other organ systems, and this might be associated with interindividual differences in not only genetic backgrounds but also cell populations and microenvironment. Single-cell omics enables assessment of cell populations, functional states, and intercellular communications and thus can enhance patientspecific understanding of diseases alongside the use of existing diagnostic tools. Kim et al. exemplified how single-cell analysis can facilitate a personalized therapeutic approach in a patient with drug-induced hypersensitivity syndrome/drug reaction with eosinophilia and systemic symptoms (81). Such an application to cardiovascular diseases is expected in the near future. 
TABLE 4 | Summary of studies of heart failure.

\begin{tabular}{|c|c|c|c|c|c|}
\hline References & Species & Model/disease & Target tissues/cells & Modalities & Major findings \\
\hline See et al. (72) & Mouse/human & TAC/DCM & $\begin{array}{l}\text { Nuclei of CMs isolated from LVs of mice } 8 \\
\text { weeks after TAC or sham } \\
\text { surgery/end-stage DCM patients or } \\
\text { control }\end{array}$ & snRNA-seq & $\begin{array}{l}\text { WGCNA revealed a disease module in which IncRNAs Gas5 and Sghrt were } \\
\text { identified as core genes and were correlated with Nppa, Nppb, and Ccng1. NPPA } \\
\text { and NPPB were also upregulated in human DCM CMs }\end{array}$ \\
\hline Nomura et al. (73) & Mouse/human & TAC/DCM & $\begin{array}{l}\text { CMs isolated from LVs of mice after sham } \\
\text { surgery or } 3 \text { days and } 1,2,4 \text {, and } 8 \text { weeks } \\
\text { after TAC/DCM patients or normal control }\end{array}$ & $\begin{array}{l}\text { scRNA-seq, } \\
\text { ChIP-seq }\end{array}$ & $\begin{array}{l}\text { Early hypertrophy was associated with ERK } 1 / 2 \text { and NRF } 1 / 2 \text { transcriptional } \\
\text { networks independent from p53. Activated p53 signaling in late hypertrophy } \\
\text { facilitated the heart failure gene program, which was conserved between humans } \\
\text { and mice }\end{array}$ \\
\hline Ren et al. (74) & Mouse/human & TAC/DCM or HCM & $\begin{array}{l}\text { CMs and non-CMs isolated from LVs of } \\
\text { mice after sham or 2, 5, 8, and } 11 \text { weeks } \\
\text { after TAC/end-stage DCM, HCM patients, } \\
\text { and control }\end{array}$ & scRNA-seq & $\begin{array}{l}\text { The dynamics of various cell types in the spectrum of heart failure were revealed. } \\
\text { Macrophage switching toward a pro-inflammatory state and their considerable } \\
\text { interaction with CMs were associated with deterioration of cardiac function, which } \\
\text { could be ameliorated by dapagliflozin }\end{array}$ \\
\hline Wang et al. (10) & Human & $\begin{array}{l}\text { Ischemic HF or } \\
\text { DCM }\end{array}$ & $\begin{array}{l}\text { CMs and non-CMs from biopsy samples } \\
\text { of LA and LVs of normal, failed and } \\
\text { recovered adult human hearts }\end{array}$ & scRNA-seq & $\begin{array}{l}\text { A comprehensive resource of single-cell transcriptomes of both CMs and } \\
\text { non-CMs from normal, failed, and recovered human heart was constructed. } \\
\text { ACKR1 } 1^{+} \text {ECs with a protective function decreased in failed hearts. Injection of } \\
\text { ACKR1 }{ }^{+} \text {ECs rescued cardiac function after Ml by increasing vessel density in } \\
\text { both infarct and border region in mice }\end{array}$ \\
\hline Zaman et al. (75) & Mouse & Angiotensin II & $\begin{array}{l}\text { Sorted cardiac macrophages from mice } \\
\text { after } 4 \text { or } 28 \text { days of angiotensin II infusion } \\
\text { or sham }\end{array}$ & scRNA-seq & $\begin{array}{l}\text { Cardiac macrophages exposed to hypertensive stress were enriched in reparative } \\
\text { pathways encompassing Igf1. Either depletion of tissue-resident macrophages or } \\
\text { conditional knockout of lgf1 in tissue-resident macrophages inhibited adaptive CM } \\
\text { hypertrophy and thus led to cardiac dysfunction }\end{array}$ \\
\hline $\begin{array}{l}\text { Ramanujam et al. } \\
\text { (76) }\end{array}$ & Mouse & TAC & $\begin{array}{l}\text { Non-CMs from pressure-overloaded } \\
\text { hearts } 6 \text { days after TAC in wild-type and } \\
\text { macrophage-specific miR-21-deficient } \\
\text { mice }\end{array}$ & scRNA-seq & $\begin{array}{l}\text { Macrophage-specific deficiency of miR-21 resulted in less fibrosis and attenuated } \\
\text { cardiac dysfunction in pressure-overloaded murine hearts. Cardiac macrophages } \\
\text { were primary paracrine inducers of fibroblast activation possibly via secreted } \\
\text { proteins such as TGF } \beta \text { and fibronectin, which was mediated by macrophage } \\
\text { miR-21 }\end{array}$ \\
\hline Martini et al. (77) & Mouse & TAC & $\begin{array}{l}\text { CD45 } 4 \text { cells from LVs of mice } 1 \text { or } 4 \\
\text { weeks after TAC/sham }\end{array}$ & scRNA-seq & $\begin{array}{l}\text { Upon pressure overload, immune activation occurred across the entire range of } \\
\text { immune cell types, leading to upregulation of key subset-specific molecules, such } \\
\text { as Osm in pro-inflammatory macrophages and Pdcd1 in regulatory T cells }\end{array}$ \\
\hline
\end{tabular}

ChIP-seq, chromatin immunoprecipitation with parallel sequencing; CM, cardiomyocyte; DCM, dilated cardiomyopathy; HCM, hypertrophic cardiomyopathy; HF, heart failure; IncRNA, long non-coding RNA; LA, left atria; LV, left ventricle; scRNA-seq, single-cell RNA sequencing; snRNA-seq, single-nucleus RNA sequencing; TAC, transverse aorta constriction; WGCNA, weighted gene co-expression network analysis. 


\section{AUTHOR CONTRIBUTIONS}

ZD: writing_-original draft preparation. SN: writing_-review and editing, supervision, and funding acquisition. Both authors have approved the submitted version and agreed to be accountable for the content of the work.

\section{FUNDING}

This work was supported by grants from a Grant-in-Aid for Young Scientists (to SN), the Japan Foundation for Applied Enzymology (to SN), the SENSHIN Medical Research Foundation (to SN), the Kanae Foundation for the Promotion of

\section{REFERENCES}

1. Buenrostro JD, Wu B, Litzenburger UM, Ruff D, Gonzales ML, Snyder MP, et al. Single-cell chromatin accessibility reveals principles of regulatory variation. Nature. (2015) 523:486-90. doi: 10.1038/nature14590

2. Islam S, Zeisel A, Joost S, La Manno G, Zajac P, Kasper M, et al. Quantitative single-cell RNA-seq with unique molecular identifiers. Nat Methods. (2014) 11:163-6. doi: 10.1038/nmeth.2772

3. Regev A, Teichmann SA, Lander ES, Amit I, Benoist C, Birney E, et al. The human cell atlas. Elife. (2017) 6:e27041. doi: 10.7554/eLife.27041

4. Tabula Muris Consortium. Single-cell transcriptomics of 20 mouse organs creates a Tabula Muris. Nature. (2018) 562:36772. doi: 10.1038/s41586-018-0590-4

5. Longo SK, Guo MG, Ji AL, Khavari PA. Integrating single-cell and spatial transcriptomics to elucidate intercellular tissue dynamics. Nat Rev Genet. (2021) 22:627-44. doi: 10.1038/s41576-021-00370-8

6. Paik DT, Cho S, Tian L, Chang HY, Wu JC. Single-cell RNA sequencing in cardiovascular development, disease and medicine. Nat Rev Cardiol. (2020) 17:457-73. doi: 10.1038/s41569-020-0359-y

7. Yamada S, Nomura S. Review of single-cell RNA sequencing in the heart. Int J Mol Sci. (2020) 21:218345. doi: 10.3390/ijms21218345

8. Kannan S, Miyamoto M, Lin BL, Zhu R, Murphy S, Kass DA, et al. Large particle fluorescence-activated cell sorting enables high-quality single-cell RNA sequencing and functional analysis of adult cardiomyocytes. Circ Res. (2019) 125:567-9. doi: 10.1161/CIRCRESAHA.119.315493

9. Katoh M, Nomura S, Yamada S, Aburatani H, Komuro I. Single-cardiomyocyte RNA sequencing to dissect the molecular pathophysiology of the heart. Methods Mol Biol. (2021) 2320:18392. doi: 10.1007/978-1-0716-1484-6_18

10. Wang L, Yu P, Zhou B, Song J, Li Z, Zhang M, et al. Single-cell reconstruction of the adult human heart during heart failure and recovery reveals the cellular landscape underlying cardiac function. Nat Cell Biol. (2020) 22:10819. doi: 10.1038/s41556-019-0446-7

11. Selewa A, Dohn R, Eckart H, Lozano S, Xie B, Gauchat E, et al. Systematic comparison of high-throughput single-cell and single-nucleus transcriptomes during cardiomyocyte differentiation. Sci Rep. (2020) 10:1535. doi: 10.1038/s41598-020-58327-6

12. Lacar B, Linker SB, Jaeger BN, Krishnaswami SR, Barron JJ, Kelder MJE, et al. Nuclear RNA-seq of single neurons reveals molecular signatures of activation. Nat Commun. (2016) 7:11022. doi: 10.1038/ncomms11022

13. Bakken TE, Hodge RD, Miller JA, Yao Z, Nguyen TN, Aevermann B, et al. Single-nucleus and single-cell transcriptomes compared in matched cortical cell types. PLoS ONE. (2018) 13:e0209648. doi: 10.1371/journal.pone.0209648

14. Bergmann O, Zdunek S, Felker A, Salehpour M, Alkass K, Bernard S, et al. Dynamics of cell generation and turnover in the human heart. Cell. (2015) 161:1566-75. doi: 10.1016/j.cell.2015.05.026

15. Jia G, Preussner J, Chen X, Guenther S, Yuan X, Yekelchyk M, et al. Single cell RNA-seq and ATAC-seq analysis of cardiac progenitor cell transition states and lineage settlement. Nat Commun. (2018) 9:4877. doi: 10.1038/s41467-018-07307-6
Medical Science (to SN), MSD Life Science Foundation (to SN), the Tokyo Biomedical Research Foundation (to SN), Astellas Foundation for Research on Metabolic Disorders (to SN), the Novartis Foundation (Japan) for the Promotion of Science (to SN), the Japanese Circulation Society (to SN), the Takeda Science Foundation (to SN), the Cell Science Research Foundation (to SN), a Grant-in-Aid for Scientific Research (B) (to SN), and AMED (JP21ek0210152, JP21gm6210010, JP20bm0704026, JP21ek0210141, JP21ek0109440, JP21ek0109487, JP21gm0810013, JP21km0405209, JP21ek0210118, JP21ek0109406, JP21ek0109543, JP21ek0109569, and JP21tm0724601).

16. Wang Z, Cui M, Shah AM, Tan W, Liu N, Bassel-Duby R, et al. Cell-type-specific gene regulatory networks underlying murine neonatal heart regeneration at single-cell resolution. Cell Rep. (2020) 33:108472. doi: 10.1016/j.celrep.2020.108472

17. Rao A, Barkley D, Franca GS, Yanai I. Exploring tissue architecture using spatial transcriptomics. Nature. (2021) 596:21120. doi: 10.1038/s41586-021-03634-9

18. Chan SS, Chan HHW, Kyba M. Heterogeneity of Mesp1+ mesoderm revealed by single-cell RNA-seq. Biochem Biophys Res Commun. (2016) 474:46975. doi: 10.1016/j.bbrc.2016.04.139

19. Lescroart F, Wang X, Lin X, Swedlund B, Gargouri S, Sanchez-Danes A, et al. Defining the earliest step of cardiovascular lineage segregation by single-cell RNA-seq. Science. (2018) 359:1177-81. doi: 10.1126/science.aao4174

20. DeLaughter DM, Bick AG, Wakimoto H, McKean D, Gorham JM, Kathiriya IS, et al. Single-cell resolution of temporal gene expression during heart development. Dev Cell. (2016) 39:480-90. doi: 10.1016/j.devcel.2016.10.001

21. Li G, Xu A, Sim S, Priest JR, Tian X, Khan T, et al. Transcriptomic profiling maps anatomically patterned subpopulations among single embryonic cardiac cells. Dev Cell. (2016) 39:491-507. doi: 10.1016/j.devcel.2016.10.014

22. Xiong H, Luo Y, Yue Y, Zhang J, Ai S, Li X, et al. Single-cell transcriptomics reveals chemotaxis-mediated intraorgan crosstalk during cardiogenesis. Circ Res. (2019) 125:398-410. doi: 10.1161/CIRCRESAHA.119.315243

23. Ivanovitch K, Soro-Barrio P, Chakravarty P, Jones RA, Bell DM, Mousavy Gharavy SN, et al. Ventricular, atrial, and outflow tract heart progenitors arise from spatially and molecularly distinct regions of the primitive streak. PLoS Biol. (2021) 19:e3001200. doi: 10.1371/journal.pbio.3001200

24. de Soysa TY, Ranade SS, Okawa S, Ravichandran S, Huang Y, Salunga HT, et al. Single-cell analysis of cardiogenesis reveals basis for organ-level developmental defects. Nature. (2019) 572:120-4. doi: 10.1038/s41586-019-1414-X

25. Xiao Y, Hill MC, Zhang M, Martin TJ, Morikawa Y, Wang S, et al. Hippo signaling plays an essential role in cell state transitions during cardiac fibroblast development. Dev Cell. (2018) 45:153-69 e6. doi: 10.1016/j.devcel.2018.03.019

26. Quijada P, Trembley MA, Misra A, Myers JA, Baker CD, Perez-Hernandez M, et al. Coordination of endothelial cell positioning and fate specification by the epicardium. Nat Commun. (2021) 12:4155. doi: 10.1038/s41467-021-24414-Z

27. Sereti KI, Nguyen NB, Kamran P, Zhao P, Ranjbarvaziri S, Park S, et al. Analysis of cardiomyocyte clonal expansion during mouse heart development and injury. Nat Commun. (2018) 9:754. doi: 10.1038/s41467-018-02891-z

28. Su T, Stanley G, Sinha R, D'Amato G, Das S, Rhee S, et al. Single-cell analysis of early progenitor cells that build coronary arteries. Nature. (2018) 559:356-62. doi: 10.1038/s41586-018-0288-7

29. Li G, Tian L, Goodyer W, Kort EJ, Buikema JW, Xu A, et al. Single cell expression analysis reveals anatomical and cell cycle-dependent transcriptional shifts during heart development. Development. (2019) 146:173476. doi: 10.1242/dev.173476

30. Wunnemann F, Ta-Shma A, Preuss C, Leclerc S, van Vliet PP, Oneglia A, et al. Loss of ADAMTS19 causes progressive non-syndromic heart valve disease. Nat Genet. (2020) 52:40-7. doi: 10.1038/s41588-019-0536-2 
31. Hulin A, Hortells L, Gomez-Stallons MV, O’Donnell A, Chetal K, Adam M, et al. Maturation of heart valve cell populations during postnatal remodeling. Development. (2019) 146:173047. doi: 10.1242/dev.173047

32. Wang Y, Yao F, Wang L, Li Z, Ren Z, Li D, et al. Single-cell analysis of murine fibroblasts identifies neonatal to adult switching that regulates cardiomyocyte maturation. Nat Commun. (2020) 11:2585. doi: 10.1038/s41467-020-16204-w

33. Goodyer WR, Beyersdorf BM, Paik DT, Tian L, Li G, Buikema JW, et al. Transcriptomic profiling of the developing cardiac conduction system at single-cell resolution. Circ Res. (2019) 125:379-97. doi: 10.1161/CIRCRESAHA.118.314578

34. Suryawanshi H, Clancy R, Morozov P, Halushka MK, Buyon JP, Tuschl T. Cell atlas of the foetal human heart and implications for autoimmune-mediated congenital heart block. Cardiovasc Res. (2020) 116:1446-57. doi: $10.1093 / \mathrm{cvr} / \mathrm{cvz} 257$

35. Sahara M, Santoro F, Sohlmer J, Zhou C, Witman N, Leung CY, et al. Population and single-cell analysis of human cardiogenesis reveals unique LGR5 ventricular progenitors in embryonic outflow tract. Dev Cell. (2019) 48:475-90 e7. doi: 10.1016/j.devcel.2019.01.005

36. Cui Y, Zheng Y, Liu X, Yan L, Fan X, Yong J, et al. Single-cell transcriptome analysis maps the developmental track of the human heart. Cell Rep. (2019) 26:1934-50 e5. doi: 10.1016/j.celrep.2019.01.079

37. Lahm H, Jia M, Dressen M, Wirth F, Puluca N, Gilsbach R, et al. Congenital heart disease risk loci identified by genome-wide association study in European patients. J Clin Invest. (2021) 131. doi: 10.1172/JCI141837

38. Asp M, Giacomello S, Larsson L, Wu C, Furth D, Qian X, et al. A spatiotemporal organ-wide gene expression and cell atlas of the developing human heart. Cell. (2019) 179:1647-60 e19. doi: 10.1016/j.cell.2019.11.025

39. Tyser RCV, Ibarra-Soria $\mathrm{X}$, McDole $\mathrm{K}$, Arcot Jayaram S, Godwin J, van den Brand TAH, et al. Characterization of a common progenitor pool of the epicardium and myocardium. Science. (2021) 371:abb2986. doi: 10.1126/science.abb2986

40. Mantri M, Scuderi GJ, Abedini-Nassab R, Wang MFZ, McKellar D, Shi H, et al. Spatiotemporal single-cell RNA sequencing of developing chicken hearts identifies interplay between cellular differentiation and morphogenesis. Nat Commun. (2021) 12:1771. doi: 10.1038/s41467-021-21892-z

41. Yekelchyk M, Guenther S, Preussner J, Braun T. Mono- and multi-nucleated ventricular cardiomyocytes constitute a transcriptionally homogenous cell population. Basic Res Cardiol. (2019) 114:36. doi: 10.1007/s00395-019-0744-z

42. Skelly DA, Squiers GT, McLellan MA, Bolisetty MT, Robson P, Rosenthal NA, et al. Single-cell transcriptional profiling reveals cellular diversity and intercommunication in the mouse heart. Cell Rep. (2018) 22:60010. doi: 10.1016/j.celrep.2017.12.072

43. Chakarov S, Lim HY, Tan L, Lim SY, See P, Lum J, et al. Two distinct interstitial macrophage populations coexist across tissues in specific subtissular niches. Science. (2019) 363:aau0964. doi: 10.1126/science.aau0964

44. Hulsmans M, Clauss S, Xiao L, Aguirre AD, King KR, Hanley A, et al. Macrophages facilitate electrical conduction in the heart. Cell. (2017) 169:51022 e20. doi: 10.1016/j.cell.2017.03.050

45. Linscheid N, Logantha S, Poulsen PC, Zhang S, Schrolkamp M, Egerod KL, et al. Quantitative proteomics and single-nucleus transcriptomics of the sinus node elucidates the foundation of cardiac pacemaking. Nat Commun. (2019) 10:2889. doi: 10.1038/s41467-019-10709-9

46. Liang D, Xue J, Geng L, Zhou L, Lv B, Zeng Q, et al. Cellular and molecular landscape of mammalian sinoatrial node revealed by single-cell RNA sequencing. Nat Commun. (2021) 12:287. doi: 10.1038/s41467-020-20448-x

47. Paik DT, Tian L, Williams IM, Rhee S, Zhang H, Liu C, et al. Single-cell RNA sequencing unveils unique transcriptomic signatures of organ-specific endothelial cells. Circulation. (2020) 142:1848-62. doi: 10.1161/CIRCULATIONAHA.119.041433

48. Yucel N, Axsom J, Yang Y, Li L, Rhoades JH, Arany Z. Cardiac endothelial cells maintain open chromatin and expression of cardiomyocyte myofibrillar genes. Elife. (2020) 9:e55730. doi: 10.7554/eLife.55730

49. Hu Z, Liu W, Hua X, Chen X, Chang Y, Hu Y, et al. Single-cell transcriptomic atlas of different human cardiac arteries identifies cell types associated with vascular physiology. Arterioscler Thromb Vasc Biol. (2021) 41:140827. doi: 10.1161/ATVBAHA.120.315373

50. Wolfien M, Galow AM, Muller P, Bartsch M, Brunner RM, Goldammer $\mathrm{T}$, et al. Single-nucleus sequencing of an entire mammalian heart: cell type composition and velocity. Cells. (2020) 9:20318. doi: 10.3390/cells 9020318

51. Vidal R, Wagner JUG, Braeuning C, Fischer C, Patrick R, Tombor L, et al. Transcriptional heterogeneity of fibroblasts is a hallmark of the aging heart. JCI Insight. (2019) 4:131092. doi: 10.1172/jci.insight.131092

52. Tucker NR, Chaffin M, Fleming SJ, Hall AW, Parsons VA, Bedi KC Jr, et al. Transcriptional and cellular diversity of the human heart. Circulation. (2020) 142:466-82. doi: 10.1161/CIRCULATIONAHA.119.045401

53. Litvinukova M, Talavera-Lopez C, Maatz H, Reichart D, Worth CL, Lindberg EL, et al. Cells of the adult human heart. Nature. (2020) 588:46672. doi: 10.1038/s41586-020-2797-4

54. Wang L, Yang Y, Ma H, Xie Y, Xu J, Near D, et al. Single cell dual-omics reveals the transcriptomic and epigenomic diversity of cardiac non-myocytes. Cardiovasc Res. (2021). doi: 10.1093/cvr/cvab134

55. Bajpai G, Bredemeyer A, Li W, Zaitsev K, Koenig AL, Lokshina I, et al. Tissue resident CCR2- and CCR2+ cardiac macrophages differentially orchestrate monocyte recruitment and fate specification following myocardial injury. Circ Res. (2019) 124:263-78. doi: 10.1161/CIRCRESAHA.118.314028

56. King KR, Aguirre AD, Ye YX, Sun Y, Roh JD, Ng RP Jr, et al. IRF3 and type I interferons fuel a fatal response to myocardial infarction. Nat Med. (2017) 23:1481-7. doi: 10.1038/nm.4428

57. Vafadarnejad E, Rizzo G, Krampert L, Arampatzi P, Arias-Loza AP, Nazzal Y, et al. Dynamics of cardiac neutrophil diversity in murine myocardial infarction. Circ Res. (2020) 127:e23249. doi: 10.1161/CIRCRESAHA. 120.317200

58. Xia N, Lu Y, Gu M, Li N, Liu M, Jiao J, et al. A unique population of regulatory $\mathrm{T}$ cells in heart potentiates cardiac protection from myocardial infarction. Circulation. (2020) 142:1956-73. doi: 10.1161/CIRCULATIONAHA.120.046789

59. Heinrichs M, Ashour D, Siegel J, Buchner L, Wedekind G, Heinze $\mathrm{KG}$, et al. The healing myocardium mobilises a distinct B-cell subset through a CXCL13-CXCR5-dependent mechanism. Cardiovasc Res. (2021). doi: 10.1093/cvr/cvab181

60. Gladka MM, Molenaar B, de Ruiter H, van der Elst S, Tsui H, Versteeg D, et al. Single-cell sequencing of the healthy and diseased heart reveals cytoskeletonassociated protein 4 as a new modulator of fibroblasts activation. Circulation. (2018) 138:166-80. doi: 10.1161/CIRCULATIONAHA.117.030742

61. Molenaar B, Timmer LT, Droog M, Perini I, Versteeg D, Kooijman $\mathrm{L}$, et al. Single-cell transcriptomics following ischemic injury identifies a role for B2M in cardiac repair. Commun Biol. (2021) 4:146. doi: 10.1038/s42003-020-01636-3

62. Farbehi N, Patrick R, Dorison A, Xaymardan M, Janbandhu V, WystubLis $\mathrm{K}$, et al. Single-cell expression profiling reveals dynamic flux of cardiac stromal, vascular and immune cells in health and injury. Elife. (2019) 8:e43882. doi: 10.7554/eLife.43882

63. Kretzschmar K, Post Y, Bannier-Helaouet M, Mattiotti A, Drost J, Basak $\mathrm{O}$, et al. Profiling proliferative cells and their progeny in damaged murine hearts. Proc Natl Acad Sci USA. (2018) 115:E12245-54. doi: 10.1073/pnas.1805 829115

64. Forte E, Skelly DA, Chen M, Daigle S, Morelli KA, Hon O, et al. Dynamic interstitial cell response during myocardial infarction predicts resilience to rupture in genetically diverse mice. Cell Rep. (2020) 30:3149-63 e6. doi: 10.1016/j.celrep.2020.02.008

65. Yokota T, McCourt J, Ma F, Ren S, Li S, Kim TH, et al. Type V collagen in scar tissue regulates the size of scar after heart injury. Cell. (2020) 182:545-62 e23. doi: 10.1016/j.cell.2020.06.030

66. Li Z, Solomonidis EG, Meloni M, Taylor RS, Duffin R, Dobie R, et al. Single-cell transcriptome analyses reveal novel targets modulating cardiac neovascularization by resident endothelial cells following myocardial infarction. Eur Heart J. (2019) 40:2507-20. doi: 10.1093/eurheartj/ehz305

67. Tombor LS, John D, Glaser SF, Luxan G, Forte E, Furtado M, et al. Single cell sequencing reveals endothelial plasticity with transient mesenchymal activation after myocardial infarction. Nat Commun. (2021) 12:681. doi: 10.1038/s41467-021-20905-1

68. Gladka MM, Kohela A, Molenaar B, Versteeg D, Kooijman L, Monshouwer-Kloots J, et al. Cardiomyocytes stimulate angiogenesis after ischemic injury in a ZEB2-dependent manner. Nat Commun. (2021) 12:84. doi: 10.1038/s41467-020-20361-3 
69. Kuppe C, Ramirez Flores RO Li Z, Hannani M, Tanevski J, Halder M, et al. Spatial multi-omic map of human myocardial infarction. bioRxiv. (2020). doi: 10.1101/2020.12.08.411686

70. Zhang Y, Gago-Lopez N, Li N, Zhang Z, Alver N, Liu Y, et al. Single-cell imaging and transcriptomic analyses of endogenous cardiomyocyte dedifferentiation and cycling. Cell Discov. (2019) 5:30. doi: 10.1038/s41421-019-0095-9

71. van Blokland IV, Groot HE, Franke LH, van der Wijst MGP, van der Harst P. Translational insights from single-cell technologies across the cardiovascular disease continuum. Trends Cardiovasc Med. (2021). doi: 10.1016/j.tcm.2021.02.009

72. See K, Tan WLW, Lim EH, Tiang Z, Lee LT, Li PYQ, et al. Single cardiomyocyte nuclear transcriptomes reveal a lincRNA-regulated dedifferentiation and cell cycle stress-response in vivo. Nat Commun. (2017) 8:225. doi: 10.1038/s41467-017-00319-8

73. Nomura S, Satoh M, Fujita $T$, Higo $T$, Sumida $T$, Ko $T$, et al. Cardiomyocyte gene programs encoding morphological and functional signatures in cardiac hypertrophy and failure. Nat Commun. (2018) 9:4435. doi: 10.1038/s41467-018-06639-7

74. Ren Z, Yu P, Li D, Li Z, Liao Y, Wang Y, et al. Single-cell reconstruction of progression trajectory reveals intervention principles in pathological cardiac hypertrophy. Circulation. (2020) 141:1704-19. doi: 10.1161/CIRCULATIONAHA.119.043053

75. Zaman R, Hamidzada $H$, Kantores C, Wong A, Dick SA, Wang $\mathrm{Y}$, et al. Selective loss of resident macrophage-derived insulin-like growth factor-1 abolishes adaptive cardiac growth to stress. Immunity. (2021). doi: 10.1016/j.immuni.2021.07.006

76. Ramanujam D, Schon AP, Beck C, Vaccarello P, Felician G, Dueck A, et al. MicroRNA-21-dependent macrophage-to-fibroblast signaling determines the cardiac response to pressure overload. Circulation. (2021) 143:1513-25. doi: 10.1161/CIRCULATIONAHA.120. 050682

77. Martini E, Kunderfranco P, Peano C, Carullo P, Cremonesi M, Schorn T, et al. Single-cell sequencing of mouse heart immune infiltrate in pressure overload- driven heart failure reveals extent of immune activation. Circulation. (2019) 140:2089-107. doi: 10.1161/CIRCULATIONAHA.119.041694

78. Chen L, Li X, Chen M, Feng Y, Xiong C. The ACE2 expression in human heart indicates new potential mechanism of heart injury among patients infected with SARS-CoV-2. Cardiovasc Res. (2020) 116:1097100. doi: $10.1093 / \mathrm{cvr} / \mathrm{cvaa} 078$

79. Delorey TM, Ziegler CGK, Heimberg G, Normand R, Yang Y, Segerstolpe A, et al. COVID-19 tissue atlases reveal SARS-CoV-2 pathology and cellular targets. Nature. (2021) 595:107-13. doi: 10.1038/s41586-021-03570-8

80. Mills RJ, Humphrey SJ, Fortuna PRJ, Lor M, Foster SR, Quaife-Ryan GA, et al. BET inhibition blocks inflammation-induced cardiac dysfunction and SARSCoV-2 infection. Cell. (2021) 184:2167-82 e22. doi: 10.1016/j.cell.2021.03.026

81. Kim D, Kobayashi T, Voisin B, Jo JH, Sakamoto K, Jin SP, et al. Targeted therapy guided by single-cell transcriptomic analysis in druginduced hypersensitivity syndrome: a case report. Nat Med. (2020) 26:23643. doi: 10.1038/s41591-019-0733-7

Conflict of Interest: The authors declare that the research was conducted in the absence of any commercial or financial relationships that could be construed as a potential conflict of interest.

Publisher's Note: All claims expressed in this article are solely those of the authors and do not necessarily represent those of their affiliated organizations, or those of the publisher, the editors and the reviewers. Any product that may be evaluated in this article, or claim that may be made by its manufacturer, is not guaranteed or endorsed by the publisher.

Copyright (c) 2021 Dai and Nomura. This is an open-access article distributed under the terms of the Creative Commons Attribution License (CC BY). The use, distribution or reproduction in other forums is permitted, provided the original author(s) and the copyright owner(s) are credited and that the original publication in this journal is cited, in accordance with accepted academic practice. No use, distribution or reproduction is permitted which does not comply with these terms. 